\title{
Gambaran tingkat kecemasan pada anak yang mengalami kekerasan di sekolah dasar di Kecamatan Malalayang Kota Manado
}

\author{
${ }^{1}$ Delarisa R. Lindo \\ ${ }^{2}$ Herdy Munayang \\ ${ }^{2}$ Theresia M. D. Kaunang
${ }^{1}$ Kandidat Skripsi Fakultas Kedokteran Universitas Sam Ratulangi Manado
${ }^{2}$ Bagian Psikiatri Fakultas Kedokteran Universitas Sam Ratulangi Manado \\ Email: delarisalindo@yahoo.co.id
}

\begin{abstract}
Anxiety and other psychiatric disorders such as depression, become as the most suffered mental illness. Each year, an average of 38 million people suffer from anxiety and depression. Anxiety can occur in children when they are facing stressful situations threatening their lives, inter alia violence against children. Children often feel anxious, especially when they lost of love, attention, and support from their parents. This study was aimed to obtain a description of the level of anxiety in children who had experienced violence in elementary school at Malalayang district in Manado. This was a descriptive quantitative study with a cross-sectional design using purposive sampling method. Respondents were fourth grade and sixth grade elementary school children aged 9-12 years. The instrument used was a questionnaire of Revised Children's Manifest Anxiety Scale (RCMAS). The results showed that of 315 children who had experienced violence, there were 246 children (78.09\%) had normal anxiety, 41 children (13.02\%) had mild anxiety, 21 children $(6.67 \%)$ had moderate anxiety, and 7 children $(2.22 \%)$ had severe anxiety. Conclusion: Most of the respondents who experienced anxiety as a result of violence were in the normal anxiety level.
\end{abstract}

Keywords: anxiety, child abuse, children of elementary school age, RCMAS

\begin{abstract}
Abstrak: Kecemasan dengan gangguan psikis lainnya yaitu depresi, menjadi penyakit kejiwaan yang paling banyak diderita. Setiap tahunnya rata-rata sebanyak 38 juta orang mengalami kecemasan dan depresi. Kecemasan dapat dialami oleh anak-anak ketika menghadapi situasi stres yang mengancam hidupnya, salah satunya ialah kekerasan pada anak. Anak-anak sering merasa cemas terutama bila kehilangan kasih sayang, perhatian dan dukungan dari orang tuanya. Penelitian ini bertujuan untuk mendapatkan gambaran tingkat kecemasan pada anak yang mengalami kekerasan di Sekolah Dasar (SD) di Kecamatan Malalayang Kota Manado. Jenis penelitian ialah deskriptif-kuantitatif dengan desain potong lintang dan menggunakan purposive sampling. Responden penelitian yaitu anak SD kelas IV-VI usia 9-12 tahun. Instrumen yang digunakan ialah kuesioner Revised Children's Manifest Anxiety Scale (RCMAS). Hasil penelitian memperlihatkan dari 315 anak yang mengalami kekerasan, terdapat 246 anak $(78,09 \%)$ mengalami kecemasan normal, 41 anak $(13,02 \%)$ mengalami kecemasan ringan, 21 anak $(6,67 \%)$ mengalami kecemasan sedang, dan 7 anak $(2,22 \%)$ mengalami kecemasan berat. Simpulan: Sebagian besar responden yang mengalami kecemasan akibat kekerasan berada dalam kondisi kecemasan normal.
\end{abstract}

Kata kunci: kecemasan, kekerasan pada anak, anak usia sekolah dasar, RCMAS

Kekerasan adalah segala bentuk tindakan yang disengaja dengan menggunakan kekuatan fisik dan kekuasaan terhadap orang lain atau kelompok yang 
mengakibatkan cedera, kerugian psikologis, gangguan perkembangan, dan bahkan kematian. ${ }^{1,2}$ Kekerasan pada anak adalah semua bentuk kekerasan dan penelantaran yang terjadi pada anak dibawah usia 18 tahun, mencakup semua jenis perlakuan fisik dan emosional, pelecehan seksual, penelantaran, kelalaian dan komersial atau eksploitasi yang mengakibatkan kerugian aktual maupun potensial untuk kesehatan, kelangsungan hidup, pengembangan atau martabat anak dalam konteks hubungan tanggung jawab, kepercayaan atau
kekuasaan.

Di seluruh dunia, diperkirakan satu miliar anak mengalami pelecehan setiap tahunnya dengan tingkat tertinggi di negara berpenghasilan rendah dan menengah dan khususnya di wilayah Afrika. ${ }^{5-7} \mathrm{Di}$ Afrika angka kekerasan fisik pada anak dapat mencapai $64 \%$, kekerasan seksual pada anak laki-laki mencapai 56\% dan 53\% pada anak perempuan. ${ }^{8}$ Menurut WHO, setiap tahun 40 juta anak dibawah usia 14 tahun menjadi korban kekerasan dan penelantaran di seluruh dunia. ${ }^{8}$ Sebuah studi internasional mengatakan bahwa seperempat dari semua orang dewasa pernah mengalami kekerasan secara fisik ketika masih anak-anak. Selain itu 1 dari 5 wanita dan 1 dari 13 pria pernah mengalami pelecehan seksual pada masa anak-anak. $^{3}$

Tingginya angka kekerasan terhadap anak juga dibuktikan oleh data dari Komisi Nasional Perlindungan Anak Indonesia (KPAI). Hasil pemantauan KPAI dari tahun 2011 sampai tahun 2014 menunjukkan terjadi peningkatan yang signifikan yaitu dari 2.178 menjadi 5.066 kasus kekerasan. ${ }^{9}$ Tahun 2015 jumlah kasus kekerasan mengalami penurunan menjadi 1.698 kasus, hal ini disebabkan oleh adanya gerakan masif melawan kekerasan pada anak dari pemerintah. Namun ironisnya pada akhir bulan Maret tahun 2016, kekerasan dan keterlibatan anak terhadap masalah hukum naik sebesar $15 \%$ dengan total laporan mencapai 645 kasus. ${ }^{10,11}$

Menurut Badan Pemberdayaan Perempuan dan Perlindungan Anak (BP3A)
Provinsi Sulawesi Utara menyebutkan bahwa di Kota Manado jumlah kasus kekerasan pada anak tahun 2013-2015 cenderung mengalami peningkatan. Jumlah kasus yang dilaporkan pada tahun 2013 dan 2014 sebanyak 21 kasus dan 19 kasus. Pada tahun 2015 jumlah kekerasan pada anak mengalami peningkatan sebanyak 78 kasus. Data terakhir yang masuk pada bulan Januari 2016-Februari 2016 yaitu sebanyak 7 kasus. $^{12}$

Dari sejumlah penelitian mengenai kekerasan terhadap anak membuktikan bahwa kekerasan semacam itu ada di setiap negara di dunia yang melintasi budaya, kelas, pendidikan, tingkat pendapatan dan asal-usul etnis. Kekerasan pada anak harus mendapatkan perhatian yang serius dari semua pihak terkait, karena menyangkut masa depan anak dan sangat mungkin meninggalkan trauma yang mendalam. Ironisnya, para pelaku kekerasan justru adalah orang yang dekat dengan anak. Sebanyak $24 \%$ pelaku berasal dari keluarga, $56 \%$ dari lingkungan sosial sekitar tempat tinggal anak, dan sebanyak $17 \%$ dari lingkungan sekolah. ${ }^{13}$ Kekerasan pada anak dipaksakan secara aktif maupun pasif pada anak dibawah umur oleh orang tua atau orang lain yang memberikan kerugian baik secara fisik maupun psikologis. ${ }^{14}$ Salah satu kerugian psikologis yang dapat dialami anak ialah kecemasan. Menurut Kaplan kecemasan adalah respon terhadap suatu ancaman yang sumbernya tidak diketahui, internal, samar-samar, atau konfliktual yang menyadarkan dan memperingatkan adanya bahaya yang mengancam dan memungkinkan seseorang mengambil tindakan untuk mengatasi ancaman. ${ }^{15}$

Data dari National Institute of Health, Amerika Serikat menyatakan bahwa kecemasan dengan gangguan psikis lainnya yaitu depresi menjadi penyakit kejiwaan yang paling banyak diderita. Setiap tahunnya rata-rata sebanyak 38 juta orang mengalami kecemasan dan depresi. ${ }^{16,17}$ Anak usia SD (6-12 tahun) sering merasa cemas ketika kehilangan kasih sayang, perhatian, dan dukungan orang tuanya, 
terutama bila anak mendapatkan kekerasan dari orang tuanya. ${ }^{18,19}$ Jika kecemasan dan ketakutan berlangsung untuk waktu yang lama, maka anak akan mengalami gangguan tidur, depresi, kesulitan bergaul dan berteman, penyalahgunaan obatobatan, dan penurunan sistem kekebalan tubuh yang dapat membuat anak lebih rentan terhadap berbagai penyakit tertentu. ${ }^{20,21}$

Sampai saat ini belum ada data mengenai gambaran tingkat kecemasan pada anak yang mengalami kekerasan, khususnya di Kota Manado. Penelitian ini bertujuan untuk mendapatkan gambaran tingkat kecemasan pada anak yang mengalami kekerasan di SD di Kecamatan Malalayang Kota Manado.

\section{METODE PENELITIAN}

Jenis penelitian ini ialah deskriptifkuantitatif dengan menggunakan desain potong lintang dengan teknik pengambilan sampel menggunakan teknik purposive sampling. Besar sampel pada penelitian ini berdasarkan pada hasil skrining yang dilakukan oleh Radja di 6 SD pada anak yang berusia 9-12 tahun di kelas IV sampai kelas VI yang berada di Kecamatan Malalayang Kota Manado pada tahun $2016 .^{21}$ Raja melakukan skrining pada 316 anak dan mendapatkan 315 anak yang mengalami kekerasan (data sekunder) yang memenuhi kriteria inklusi dan menjadi sampel dalam penelitian ini.

Pengumpulan data dilakukan dengan menggunakan kuesioner Revised Children's Manifest Anxiety Scale (RCMAS) untuk menilai tingkat kecemasan pada anak yang mengalami kekerasan (data primer) dan kuesioner data sosiodemografik yang diisi oleh orang tua yang terdiri dari jenis kelamin, usia, kelas, suku, agama, tingkat pendidikan terakhir orang tua, jenis pekerjaan orang tua dan status ekonomi keluarga. Data yang diperoleh melalui pengisian kuesioner diolah menggunakan program Microsoft Excel untuk menentukan frekuensi dan persentase dari setiap variabel yang disajikan dalam bentuk tabel.

\section{HASIL PENELITIAN}

Berdasarkan data dari kuesioner sosiodemografik, didapatkan responden terbanyak ialah anak berjenis kelamin perempuan yaitu sebanyak 168 anak $(53,33 \%)$, berusia 9 tahun sebanyak 125 anak $(39,68 \%)$, berada di kelas 6 sebanyak 130 anak $(41,27 \%)$, berasal dari suku Minahasa sebanyak 211 anak (67\%), dan beragama Kristen sebanyak 228 anak (72,38\%) (Tabel 1).

Untuk karakteristik orang tua dan status ekonomi keluarga responden, didapatkan bahwa tingkat pendidikan terakhir orang tua paling banyak berada pada jenjang SMA, yaitu 173 orang $(54,92 \%)$ untuk ayah dan 185 orang $(58,73 \%)$ untuk ibu. Jenis pekerjaan orang tua responden yang paling banyak ialah sebagai karyawan swasta untuk ayah yaitu sebanyak 112 orang $(35,56 \%)$ dan Ibu Rumah Tangga (IRT) untuk ibu yaitu sebanyak 198 orang $(62,86 \%)$ (Tabel 2). Untuk status ekonomi keluarga, dari 306 anak didapatkan sebanyak 125 anak $(39,68 \%)$ berada pada tingkat ekonomi menengah dan terdapat 9 orang anak $(2,86 \%)$ yang status ekonomi keluarganya tidak diisi pada saat pengambilan data (Tabel 3). Pembagian status ekonomi keluarga yaitu pendapatan/bulan Rp.500.000-Rp.1.000.000 = ekonomi bawah; pendapatan/bulan Rp.1.000.000Rp.2.000.000 = ekonomi menengah; dan pendapatan/bulan >Rp.2.000.000 = ekonomi atas.

Untuk mengetahui bagaimana tingkat kecemasan pada anak yang mengalami kekerasan di 6 SD di Kecamatan Malalayang Kota Manado, peneliti membagi tingkat kecemasan menjadi 4 tingkatan, yaitu kecemasan normal, kecemasan ringan, kecemasan sedang, dan kecemasan berat. Hasilnya didapatkan bahwa anak usia sekolah yang mengalami kekerasan paling banyak berada dalam kondisi kecemasan normal, yaitu sebanyak 246 anak (78,09\%) (Tabel 4). 
Lindo, Munayang, Kaunang: Gambaran tingkat kecemasan...

Tabel 1. Distribusi karakteristik anak usia sekolah di 6 SD di Kecamatan Malalayang Kota Manado yang berdasarkan pada jenis kelamin, usia, kelas, suku, dan agama

\begin{tabular}{|c|c|c|}
\hline Jenis kelamin & Frekuensi & $(\%)$ \\
\hline Laki-laki & 147 & 46,67 \\
\hline Perempuan & 168 & 53,33 \\
\hline \multicolumn{3}{|l|}{ Usia } \\
\hline 9 tahun & 125 & 39,68 \\
\hline 10 tahun & 112 & 35,56 \\
\hline 11 tahun & 72 & 22,86 \\
\hline 12 tahun & 6 & 1,90 \\
\hline \multicolumn{3}{|l|}{ Kelas } \\
\hline Kelas 4 & 69 & 21,90 \\
\hline Kelas 5 & 116 & 36,83 \\
\hline Kelas 6 & 130 & 41,27 \\
\hline \multicolumn{3}{|l|}{ Suku } \\
\hline Minahasa & 211 & 67,00 \\
\hline Sanger & 33 & 10,47 \\
\hline Gorontalo & 26 & 8,25 \\
\hline Jaton & 1 & 0,32 \\
\hline Kotamobagu & 1 & 0,32 \\
\hline Batak & 3 & 0,95 \\
\hline Papua & 1 & 0,32 \\
\hline Jawa & 22 & 6,97 \\
\hline Makassar & 1 & 0,32 \\
\hline NTT & 1 & 0,32 \\
\hline NTB & 1 & 0,32 \\
\hline Banjarmasin & 1 & 0,32 \\
\hline Bugis & 1 & 0,32 \\
\hline Toraja & 1 & 0,32 \\
\hline Ambon & 4 & 1,26 \\
\hline Ternate & 1 & 0,32 \\
\hline Riau & 1 & 0,32 \\
\hline Padang & 1 & 0,32 \\
\hline Bali & 3 & 0,95 \\
\hline Tiong Hoa & 1 & 0,32 \\
\hline \multicolumn{3}{|l|}{ Agama } \\
\hline Kristen & 228 & 72,38 \\
\hline Katolik & 13 & 4,13 \\
\hline Islam & 72 & 22,86 \\
\hline Hindu & 2 & 0,63 \\
\hline Buddha & 0 & 0,00 \\
\hline Kong $\mathrm{Hu} \mathrm{Cu}$ & 0 & 0,00 \\
\hline
\end{tabular}

Tabel 2. Distribusi karakteristik orang tua responden berdasarkan pada tingkat pendidikan terakhir dan jenis pekerjaan

\begin{tabular}{ccccc}
\hline Tingkat & \multicolumn{2}{c}{ Frekuensi } & \multicolumn{2}{c}{$(\%)$} \\
\cline { 2 - 5 } Pendidikan & Ayah & Ibu & Ayah & Ibu \\
\hline SD & 14 & 15 & 4.44 & 4.76 \\
SMP & 45 & 51 & 14.29 & 16.19 \\
SMA & 173 & 185 & 54.92 & 58.73 \\
S1 & 64 & 47 & 20.32 & 14.92 \\
S2 & 8 & 7 & 2.54 & 2.22 \\
S3 & 2 & 1 & 0.63 & 0.32 \\
D1 & 1 & 5 & 0.32 & 1.59 \\
D2 & 1 & 0 & 0.32 & 0.00 \\
D3 & 7 & 4 & 2.22 & 1.27 \\
\hline Jenis & & & & \\
pekerjaan & & & & \\
\hline Wiraswasta & 50 & 26 & 15.87 & 8.25 \\
PNS & 39 & 30 & 12.38 & 9.52 \\
Karyawan & 112 & 37 & 35.56 & 11.75 \\
Swasta & & & & \\
Petani & 4 & 1 & 1.27 & 0.32 \\
Dosen & 7 & 3 & 2.22 & 0.95 \\
Honorer & 3 & 7 & 0.95 & 2.22 \\
Pendeta & 1 & 1 & 0.32 & 0.32 \\
Guru & 3 & 6 & 0.95 & 1.90 \\
Perawat & 1 & 1 & 0.32 & 0.32 \\
Buruh & 51 & 0 & 16.19 & 0.00 \\
Sopir & 13 & 0 & 4.13 & 0.00 \\
BUMN & 3 & 0 & 0.95 & 0.00 \\
Polisi & 8 & 0 & 2.54 & 0.00 \\
Arsitek & 2 & 0 & 0.63 & 0.00 \\
Wartawan & 1 & 0 & 0.32 & 0.00 \\
Nelayan & 3 & 0 & 0.95 & 0.00 \\
Tukang & 6 & 0 & 1.90 & 0.00 \\
Ojek & & & & \\
Satpam & 3 & 0 & 0.95 & 0.00 \\
Pelaut & 3 & 0 & 0.95 & 0.00 \\
Tentara & 2 & 0 & 0.63 & 0.00 \\
IRT & 0 & 198 & 0.00 & 62.86 \\
Anggota & 0 & 2 & 0.00 & 0.63 \\
Dewan & & & & \\
Tukang & 0 & 2 & 0.00 & 0.63 \\
Cuci & & & & \\
Dokter & 0 & 1 & 0.00 & 0.32 \\
Wiraswasta & 50 & 26 & 15.87 & 8.25 \\
PNS & 39 & 30 & 12.38 & 9.52 \\
\hline & & & &
\end{tabular}


Tabel 3. Distribusi status ekonomi keluarga responden

\begin{tabular}{ccc}
\hline Status ekonomi & Frekuensi & $\mathbf{( \% )}$ \\
\hline Ekonomi bawah & 60 & 19.05 \\
Ekonomi menengah & 125 & 39.68 \\
Ekonomi atas & 121 & 38.41 \\
Tidak diketahui & 9 & 2.86 \\
\hline
\end{tabular}

Tabel 4. Distribusi Frekuensi Tingkat Kecemasan Pada Anak Usia SD yang Mengalami Kekerasan di 6 SD di Kecamatan Malalayang Kota Manado

\begin{tabular}{ccc}
\hline Tingkat kecemasan & Frekuensi & $\mathbf{( \% )}$ \\
\hline Kecemasan normal & 246 & 78.09 \\
Kecemasan ringan & 41 & 13.02 \\
Kecemasan sedang & 21 & 6.67 \\
Kecemasan berat & 7 & 2.22 \\
\hline
\end{tabular}

\section{BAHASAN}

Berdasarkan pada penelitian yang dilakukan pada 315 anak yang mengalami kekerasan, didapatkan bahwa jumlah responden didominasi oleh anak perempuan yaitu sebanyak 168 anak $(53,33 \%)$ dibandingkan dengan anak lakilaki yang hanya sebanyak 147 anak $(46,67 \%)$.

Sebagian besar anak yang menjadi responden berada di kelas 6. Anak yang berusia 9 dan 10 tahun menjadi responden terbanyak dalam penelitian ini, yaitu sebanyak 125 anak $(39,68 \%)$ dan 112 anak $(35,56 \%)$. Menurut CDC perkembangan anak usia sekolah 9-11 tahun sangat dipengaruhi oleh persahabatan. Persahabatan yang sehat sangat penting dalam perkembangan anak, selain itu pada masa ini anak telah mampu menghadapi lebih banyak tantangan akademis di sekolah, menjadi lebih mandiri dalam keluarga dan mulai memahami dengan jelas sudut pandang orang lain. ${ }^{22}$

Responden yang berpartisipasi dalam penelitian ini kebanyakan berasal dari suku Minahasa yang merupakan mayoritas suku di Kota Manado. ${ }^{23}$ Hanya sebagian kecil suku yang berasal dari non-Minahasa, seperti suku Jaton, Kotamobagu, Papua, Makassar, NTT, NTB, Banjarmasin, Bugis, Toraja, Ternate, Riau, Padang, dan Tiong Hoa.
Didapatkan juga bahwa hampir semua responden beragama Kristen dikarenakan mayoritas agama di Manado ialah Kristen sehingga merupakan suatu hal yang wajar jika responden terbanyak pada penelitian ini beragama Kristen. Hal ini sesuai dengan hasil dari sensus penduduk di Kota Manado pada tahun 2010 dimana sebagian besar penduduk didominasi oleh penduduk yang beragama Kristen yaitu sebanyak $62 \%$ dari total penduduk. Agama yang lain sebanyak $31 \%$ untuk agama Islam, 5\% untuk agama Katolik, $1 \%$ untuk agama Buddha, 0,5\% untuk agama Hindu, dan 0,5\% untuk agama Kong $\mathrm{Hu} \mathrm{Cu}{ }^{24}$

Kebanyakan orang tua dari responden mencapai SMA sebagai tingkat pendidikan terakhir dan sebagian besar bekerja sebagai karyawan swasta untuk ayah dan IRT untuk ibu. Dari hasil yang didapatkan rata-rata tingkat ekonomi dari keluarga responden temasuk pada tingkat ekonomi menengah, yaitu berkisar antara Rp.1.000.000-Rp. 2.000.000.

Prevalensi tingkat kecemasan pada anak usia SD yang mengalami kekerasan di 6 SD Kecamatan Malalayang Kota Manado

Berdasarkan hasil data yang telah diolah, terdapat 69 anak $(21,91 \%)$ dari 315 anak yang mengalami kecemasan akibat kekerasan, diantaranya kecemasan ringan sebanyak 41 anak (13,02\%), kecemasan sedang sebanyak 21 anak $(6,67 \%)$, dan kecemasan berat sebanyak 7 anak $(2,22 \%)$. Sebagian besar anak yang mengalami kekerasan berada dalam tingkat kecemasan normal yaitu sebanyak 246 anak $(78,09 \%)$, hal ini disebabkan karena kecemasan merupakan suatu hal yang normal bagi manusia.

Menurut Kumar ${ }^{25}$ kecemasan bukanlah suatu penyakit, melainkan suatu gejala yang memberikan reaksi normal yang berlangsung dengan cepat terhadap situasi stres. Hal ini sejalan dengan teori dari Kaplan dan Sadock yang menyatakan bahwa kecemasan dapat dikonseptualisasikan sebagai respon normal dan adaptif yang dapat mengarahkan seseorang untuk 
mengambil tindakan yang diperlukan untuk mencegah ancaman dan mengurangi akibat yang ditimbulkannya. ${ }^{15}$

Penelitian ini dapat dikaitkan dengan penelitian yang dilakukan oleh Banducci et al. $^{26}$ pada 244 remaja di Amerika Serikat yang melakukan penilaian pada Childhood Emotional Abuse (CEA) dan Distress Tolerance (DT) yang rendah sebagai faktor yang memengaruhi kecemasan. Kedua faktor ini diukur setiap tahun dalam 5 tahun dengan menggunakan Revised Child Anxiety and Depression Scale, Childhood Trauma Questionnaire, dan Behavioral Indicator of Resiliency to Distress. Hasil yang didapatkan bahwa DT secara signifikan memengaruhi hubungan antara CEA dan kecemasan, sehingga remaja dengan CEA yang tinggi dan DT yang rendah akan memiliki kecemasan tertinggi pada peniliaian setiap tahun dan memiliki tingkat tertinggi dari gejala kecemasan di setiap waktu. ${ }^{26}$

Selain itu penelitian ini juga dapat dikaitkan dengan penelitian yang dilakukan oleh Prabowo yang menilai pengaruh senam otak terhadap tingkat kecemasan pada 34 anak SD kelas I di Yogyakarta dengan menggunakan RCMAS. Hasil yang didapatkan pada saat pretest menunjukkan bahwa banyak anak yang mengalami tingkat kecemasan sedang namun setelah diberikan intervensi, hasil yang didapatkan pada saat posttest menunjukkan bahwa tingkat kecemasan paling banyak berada pada kecemasan ringan. ${ }^{27}$

Keterbatasan penelitian terdapat pada proses pengambilan data pada saat penelitian berlangsung, yaitu waktu yang diberikan dari pihak sekolah sangat terbatas dan tempat duduk dari setiap anak sangat berdekatan sehingga anak sering mengalami gangguan dari teman sekelasnya. Adanya gangguan dari teman sekelas yang lain yang suka menengok dan saling mengejek jawaban, tentunya akan sangat memengaruhi jawaban dari setiap pertanyaan.

Pada proses pengambilan data, keterbatasan juga didapatkan pada orang tua dari responden yang tidak mengisi tingkat pendapatan keluarganya per bulan, sehingga hanya terdapat 306 anak saja yang datanya dapat diolah dan ditentukan status ekonomi keluarga.

\section{SIMPULAN}

Berdasarkan hasil penelitian yang telah dilakukan, sebagian besar responden ialah anak perempuan, usia 9 tahun, berada di kelas 6, berasal dari suku Minahasa, dan beragama Kristen. Sebagian besar tingkat pendidikan terakhir dari orang tua responden berada pada jenjang SMA baik untuk ayah maupun untuk ibu. Jenis pekerjaan dari orang tua responden yang paling banyak ialah karyawan swasta untuk ayah dan sebagai IRT untuk ibu. Tingkat ekonomi dari keluarga responden yang paling banyak ialah tingkat ekonomi menengah.

Tingkat kecemasan pada anak yang mengalami kekerasan paling banyak berada pada kondisi normal $(78,09 \%)$ dan yang paling sedikit berada pada kecemasan berat $(2,22 \%)$.

\section{SARAN}

Perlu dilakukan penelitian lanjutan seperti penilaian tingkat kecemasan yang dialami oleh anak pada saat sebelum dan setelah mendapatkan intervensi. Selain itu juga dapat dilakukan penelitian mengenai hubungan tingkat kecemasan pada anak yang mengalami kekerasan dan pada anak yang tidak mengalami kekerasan serta faktor-faktor risiko yang dapat memengaruhi dan menyebabkan timbulnya kecemasan pada anak.

Pemerintah di Indonesia telah membuat berbagai macam peraturan perundang-undangan yang berhubungan dengan kekerasan dan perlindungan pada anak, seperti Undang-Undang Nomor 23 tahun 2004 tentang Penghapusan Kekerasan dalam Rumah Tangga dan Undang-Undang Republik Indonesia Nomor 23 Tahun 2002 tentang Perlindungan Anak. Namun meskipun sudah terdapat undang-undang, masyarakat masih takut dan malu untuk melaporkan adanya tindak kekerasan pada anak. 
Oleh sebab itu pemerintah kota perlu memperhatikan dan melakukan berbagai penyuluhan kepada masyarakat tentang betapa pentingnya untuk melaporkan segala bentuk kekerasan karena hal ini sangat berdampak pada kesehatan mental anak dan menyangkut masa depan anak di kemudian hari. Selain itu masyarakat juga tidak perlu merasa takut dan malu karena terdapat UU yang merangkul dan melindungi korban serta yang menindak para pembuat kekerasan pada anak dengan hukuman yang setimpal.

Selain itu keberadaan dari tokoh agama dan tokoh masyarakat sangat penting dalam menghimbau masyarakat untuk lebih memperhatikan dan peduli pada kesehatan dan masa depan anak agar terhindar dari setiap bentuk perilaku kekerasan yang ada di masyarakat.

Pada penelitian ini didapatkan 7 orang anak yang mengalami kecemasan berat akibat kekerasan yang dialaminya. Kecemasan berat ini tentunya akan sangat memengaruhi mental dan kualitas hidup anak. Oleh sebab itu pihak-pihak yang berwenang seperti halnya lembaga-lembaga perlindungan anak dan khususnya orang tua harus lebih memperhatikan anak-anak tersebut dan bahkan memfasilitasi anak untuk mendapatkan intervensi medis dan terapi dalam mengatasi kecemasan yang dialami anak.

\section{DAFTAR PUSTAKA}

1. Center for Disease Control and Prevention. Injury pervention and control: youth violence. 21 Maret 2016. [cited 24 Agustus 2016]. Available from: http://www.cdc.gov/violenceprevention /youthviolence/definetions.html

2. Christakis D. Virtual violence council on communication and media. Pediatrics. 2016;2:138.

3. World Health Organization. Child maltreatment. July 2016. [cited 24 Agustus 2016]. Available from: http://www.who.int/ mediacentre/fact sheets/fs150/en/

4. Norman RE, Byambaa M, De R, Butchart A, Scott J, Vos T. The long-term health consequences of child physical abuse, emotional abuse, and neglect: a systematic review and meta-analysis.

PLoS Med. 2012;9:11.

5. Prevent child abuse America. Estimated annual cost of child abuse and neglect. April 2012. [cited 22 Agustus 2016]. Available from: http://www.preventchildabuse.org/imag es/research/pcaa_cost_report_2012_gell es_perlman.pdf

6. Cluver L, Meinck F, Shenderovich Y, Ward L, Romero HR, Redfern A, et al. A parenting programme to prevent abuse of adolescents in South Africa: study protocol for a randomised controlled trial. Trials. 2016;17:328

7. Yoder NH, Tol AW, Reis R, Jong TJ. Child mental health in Sierra Leone: a survey and exploratory qualitative study. Int $\mathbf{J}$ Ment Health Syst. 2016;10:48

8. Meinck F, Cluver DL, Boyes EM, Mhlongo LE. Risk and protective factors for physical and sexual abuse of children and adolescents in Africa. Trauma, Violence and Abuse. 2015;16:81-107

9. Komisi Perlindungan Anak Indonesia. Pelaku kekerasan terhadap anak tiap tahun meningkat. 2013. [cited 25 Agustus 2016]. Available from: http://www.kpai.go.id/kanal/tinjauan/

10. Komisi Perlindungan Anak Indonesia. Kekerasan terhadap anak naik $15 \%$. April 2016. [cited 30 Agustus 2016]. Available from: https://m.tempo.co/read/news/2016/04/ 15/063762948/kpai-kekerasanterhadap-anak-naik-15-persen

11. Komisi Perlindungan Anak Indonesia. Klaim kasus kekerasan pada anak meningkat. Mei 2016. [cited 25 Agustus 2016]. Available from: di http://news. metrotvnews.com/peristiwa/yNL88ZyN -kpai-klaim-kasus-kekerasan-padaanak-meningkat.

12. Pangemanan S. Kasus kekerasan perempuan dan anak Sulut meningkat. Februari 2016. Diakses pada tanggal 26 Agustus 2016 tersedia di http://manadoline.com/ ternyata-kasus-kekerasan-perempuan dan-anak-sulut-meningkat/

13. Ikatan Dokter Anak Indonesia. Mengajari kewaspadaan kekerasan seksual pada anak. 2014. [cited 24 Agustus 2016]. Available from: http://idai.or.id/publicarticles/seputar-kesehatan-anak/men gajarikewaspadaan-kekerasan-sek sualpada-anak.html

14. Netherlands Youth Institute. Combating child abuse and neglect in the Netherlands. 
Desember 2011. [cited 25 Agustus 2016]. Available from: http://www.dji.de/ fileadmin/user_upload/bibs/Daphne_re port_ The_Nether lands.pdf

15. Sadock JB, Sadock AV, Ruiz P. Kaplan \& Sadock's Synopsis of Psychiatry (11th ed). Philadelphia: Wolters Kluwer, 2015; p. 552-99.

16. Purnama SC. Kenali Berbagai Jenis Phobia dan Cara Mengatasinya (1st ed). Yogyakarta: ANDI, 2016; p. 9-10.

17. Leslie L, Hong NC, Peng HC, Sze MC, Carolyn Ho, Seow KDK, et al. Ministry of health clinical practice guidelines: anxiety disorders. Singapore Med J. 2015;56:310-6.

18. Gunarsa V. Psikologi Perkembangan Anak dan Remaja. Jakarta: Gunung Mulia; 2008; p. 6-13.

19. Rahmayanti A. Kekerasan psikis pada anak usia sekolah dasar dan implikasinya terhadap kesehatan mental [Skripsi]. Yogyakarta: Universitas Islam Negeri Sunan Keluarga; 2014.

20. National Association for mental health. anxiety and panic attacks. Februari 2015. [cited 25 Agustus 2016]. Available from: https://www.mind.org.uk/media/18924 82/ mind_anxiety_panic_web.pdf

21. Radja RD. Gambaran kekerasan pada anak sekolah dasar di kecamatan Malalayang kota Manado [Skripsi]. Manado: Fakultas Kedokteran Universitas Sam
Ratulangi; 2016.

22. Center for Disease Control and Prevention. Child development. 15 Maret 2016. [cited 29 Agustus 2016]. Available from:

http://www.cdc.gov/ncbddd/childdevel opment/positiveparenting/middle.html

23. Badan Pemeriksa Keuangan Republik Indonesia. Pemerintah Kota Manado. [cited 14 November 2016]. Available from: http://manado.bpk.go.id/?page_id=670.

24. Badan Pusat Statistik Kota Manado. Jumlah penduduk menurut kecamatan dan agama yang dianut di kota Manado, 2010. [cited 14 November 2016]. Available from: https://manadokota.bps.go.id/link TabelStatis /view/id/34

25. Kumar AC. A study on the anxiety of higher secondary students in relation to certain sociological variables. Education Chronicle. 2014;5:60.

26. Banducci AN, Lejuez CW, Dougherty LR, MacPherson L. A prospective examination of the relations between emotional abuse and anxiety: moderation by distress tolerance. Prev Sci. 2016;1:1-11.

27. Prabowo YS. Pengaruh senam otak terhadap tingkat kecemasan sosial pada anak usia sekolah kelas 1 di SD negeri tuguran gamping sleman Yogyakarta [Skripsi]. Yogyakarta: Sekolah Tinggi Ilmu Kesehatan 'Aisyiyah; 2015. 